\title{
Los aportes de Lucío Mendieta y Núñez a la institucionalización de la sociología en México (1939-1951)
}

Margarita Olvera Serrano

Introducción

Lucio Mendieta y Núñez es considerado el líder de la institucionalización de la sociología en México como disciplina autónoma independiente reconocida a nivel universitario. El Instituto de Investigaciones Sociales (IIS) de la Universidad Nacional, la Revista Mexicana de Sociología (RMS) y la Escuela Nacional de Ciencias Políticas y Sociales (ENCPys), todos ellos espacios adscritos a la actual Universidad Nacional Autónoma de México, son su legado más importante y duradero. Nacido en la Ciudad de Oaxaca en 1895, formó parte no sólo cronológicamente, sino política y vitalmente, de la llamada generación de 1915, formada por un pequeño grupo con acceso a bienes culturales de los que la mayoría de la población estaba excluida. Realizó sus estudios de bachiller en la influyente Escuela Nacional Preparatoria (ENP) de la Universidad Nacional de México y cuna de la primera recepción del positivismo francés en México; posteriormente, emprendió y culminó sus estudios como abogado en la Escuela Nacional de Jurisprudencia (ENJ). En 1920 obtuvo su título de licenciado en Derecho, con lo que ingresó al influyente gremio de los abogados.

Mendieta fue profundamente influido por el positivismo, la antropología, la etnografía y la criminología, así como por la experiencia de la Revolución de 1910 y el triunfo de su programa social, contenido en la Constitución de 1917. En general, para este personaje y su generación, las consecuencias político-prácticas de este acontecimiento abrieron una serie de expectativas de futuro que abonaron el camino de 
las ciencias sociales en México. La experiencia revolucionaria, el desplazamiento de la élite del largo periodo de la dictadura de Porfirio Díaz, así como la apertura que el nuevo régimen mostró a los universitarios que quisieron colaborar con él, transformó las expectativas de esta generación. Los dotó de una identidad intelectual y política con la que trazaron un campo práctico para nuevos saberes; asimismo, establecieron vínculos formales e informales sin los cuales no hubiese sido posible el ambicioso proyecto de formación de disciplinas sociales institucionalizadas que se puso en marcha durante los años treinta del siglo xx. En este sentido, es posible afirmar que el surgimiento de las ciencias sociales en México puede ser entendido como parte de las consecuencias de la revolución mexicana, puesto que su horizonte definió los derroteros de su institucionalización universitaria como disciplinas y como profesiones entre los años 30 y 50 del siglo $\mathrm{XX}^{1}$.

El contexto del triunfo de la revolución de 1910 condicionó el que estas ciencias se institucionalizaran en íntima relación con el poder público, con las demandas sociales surgidas del programa social de la Constitución de 1917, con los imperativos práctico-políticos derivados de la necesidad de reconstruir económica y socialmente al país y, posteriormente, se plantearan como medios para generar insumos útiles para los procesos de modernización que emprendió México. En este escenario fue que, a diferencia de las ciencias sociales en Estados Unidos y Europa, que aceptaban en general las sociedades que constituyeron como objeto de investigación, en México se insistió reiteradamente en que estas disciplinas tenían su propósito normativo central en la transformación de la sociedad.

El legado de la antropología de Manuel Gamio

La antropología, la etnografía, la economía, la criminología y la sociología en el México posrevolucionario emprendieron la tarea de redefinir sus propósitos a la luz de la agenda del programa social de la Revolución de 1910. Fueron estos campos los que aportaron los liderazgos, las protocomunidades de practicantes y los primeros esbozos y proyectos de descripción empírica de la realidad social del México de los años veinte y treinta. Los procesos de transmisión intergeneracional de la experiencia acumulada en estos campos de conocimiento a Lucio Mendieta y Núñez no pueden entenderse sin su relación como discípulo y colaborador del célebre antrópologo Manuel Gamio en la Dirección de Antropología de la Secretaría de Agricultura y

1. La economía en México se institucionaliza primero como profesión, hacia principios de la década de los años 1930, con la fundación de la Escuela Nacional de Economía. La sociología tardaría veinte años más en contar con un primer programa de formación universitaria de sociólogos. 
Fomento, desde sus años de estudiante. Esta dependencia gubernamental se había creado como parte de la ejecución de las recomendaciones del II Congreso Cientifico Panamericano, celebrado en Washington en 1915 y 1916; en él se propuso la creación de una institución, en cada una de las naciones indolatinas, que se encargara de estudiar a las poblaciones indígenas con el propósito de impulsar su desarrollo e “integrarlos a la civilización contemporánea”. Para Gamio, México estaba dividido en dos razas, en dos tradiciones y sus correspondientes mundos socioculturales: el indígena y el hispano; defendió la integración de las dos raíces ya que, a su juicio, el mestizo sería el crisol del que surgiría la nación (Vázquez, 1970). En 1921 Mendieta y Núñez llega a la Dirección de Antropología como jefe de su Departamento de Población Contemporánea por designación de Manuel Gamio, dando comienzo a una carrera como funcionario público que tuvo su eje en la relación de colaboración con Gamio en diversos proyectos de investigación y editoriales, experiencia que le abriría las puertas de la dirección del iIs hacia finales de los años treinta. En 1934 queda a su cargo la jefatura del Instituto de Investigaciones Sociales de la Dirección de Población de la Secretaría de Agricultura y Fomento; en 1936 es nombrado consejero del Departamento de Asuntos Indígenas. En estos años construye en paralelo, una sólida reputación como experto en derecho agrario que tuvo su punto de partida en 1923, cuando publica El derecho agrario en México, que fue durante muchos lustros una obra de referencia en la formación de los abogados orientados hacia este campo.

En estos años Lucio Mendieta integró, partiendo de la matriz del derecho y del positivismo aprendido en la ENP, la herencia cognitiva y normativa de la antropología. Manuel Gamio, su mentor, imprimió a la Dirección de Antropología un conjunto de objetivos en los que pueden rastrearse los antecedentes inmediatos de los que posteriormente Lucio Mendieta siguió como director del IIS: el conocimiento integral de los grupos indígenas del país, la investigación de los elementos necesarios para elevarlos, para fomentar su desarrollo físico, intelectual, moral y económico, preparar el terreno para su integración a la sociedad y formar así una nacionalidad coherente y definitiva, es decir, una verdadera patria ${ }^{2}$. Sabemos que Manuel Gamio sensibilizó tempranamente a Mendieta sobre los problemas indígenas, que le dio oportunidad de participar en trabajos de campo relacionados con célebre investigación sobre el Valle de Teotihuacán y que deja una profunda impronta en su formación. No es posible aquí profundizar en estas experiencias ni hacer justicia a la complejidad del legado que dejó a nuestro personaje, ni en su importancia para la estructuración del primer proyecto de ciencia sociológica de corte empírico con el que contó México. En su

2. Sobre la importancia sociológica de Manuel Gamio, ver González Navarro (1970), Reynosa Jaimes (2013). 
lugar y como botón de muestra de la relevancia de este vínculo haremos un trazo de una dimensión de esta conexión que consideramos especialmente significativa para entender cómo fue posible que Lucio Mendieta emprendiera con tanto éxito la tarea de formar un primer acervo de conocimiento escriturario especializado a través de la Revista Mexicana de Sociología: la experiencia de la revista Ethnos, dirigida por Manuel Gamio y de la Lucio Mendieta fue colaborador, así como director y editor en 1925, cuando aquél dejo la revista por haber sido nombrado Subsecretario de Educación Pública.

La instauración de una primera literatura especializada en ciencias sociales en México, tuvo un instrumento fundamental en las publicaciones periódicas, como muestra el alcance que tuvo, por ejemplo, la RMS (1939) desde sus primeros años hasta la fecha, o bien, otras publicaciones periódicas especializadas como El Trimestre Económico (1934) o la Revista Mexicana de Ciencias Políticas y Sociales (1955). Estas revistas, comenzaron como medios de institucionalización de las ciencias sociales en México, pero a lo largo del tiempo, adquirieron una densidad intelectual y características que terminaron convirtiéndolas en instituciones en sí mismas. Sin embargo, no comenzaron de cero, sino que partieron de experiencias editoriales previas que fueron en extremo valiosas y cuya investigación puntual es una tarea pendiente de la sociología en México. Una de las antecesoras mas antiguas de las revistas especializadas de las ciencias sociales en México fue, indudablemente Ethnos, fundada por Manuel Gamio en 1920 con la colaboración del lingüista y filólogo Pablo González Casanova e Ignacio del Castillo como secretarios de redacción. Los propósitos de esta publicación pueden entenderse dentro de un entramado que, en muchos sentidos, forma parte de las consecuencias intelectuales y científicas de la Revolución Mexicana; se buscó, sobre todo, el estudio de los fenómenos que entrañaba el desarrollo humano, bajo los principios y método de las ciencias sociales de ese entonces en Estados Unidos y Europa: historia, sociología, antropología, psicología. En ese horizonte de época, esto significó tratar de identificar qué "proporciones" de los grupos sociales que conformaban el país en ese entonces, eran conocidos científicamente y cuáles no. Desde este primer número de Ethnos se concluyó que era abrumadora la cantidad de los que no se conocían sus características y aspectos más esenciales". Los temas abordados en los primeros números de esta publicación mensual fueron, entre otros, el estado civil en México, el problema indígena, la marihuana, los descubrimientos arqueológicos en Teotihuacán, la incorporación de los Yaquis a la vida nacional, el derecho mexicano antes de la conquista. Los campos cognitivos desde los cuales fueron abordadas estas cuestiones fueron la antropología, la etnografía, el derecho, la historia, la historia y una protosociología de corte descriptivo. Estos esfuerzos editoriales tuvieron un interés político-práctico asociado a la necesidad de despertar el interés público por conocer 
realidades sociales situadas y desconocidas empíricamente. La tarea fue avanzar en la producción de un saber científico que pudiese ser un insumo cognitivo para la orientación de la acción gubernamental, para la elaboración de proyectos dirigidos al progreso de la patria. El argumento de fondo no era nuevo y su núcleo fue la convicción de que los gobernantes necesitaban con urgencia conocer las características de los grupos sociales que trataban de dirigir, que no existía un conocimiento observacional riguroso de éstos y que la antropología y las ciencias sociales podrían producirlo. La población debía ser investigada "integralmente" en sus dimensiones cuantitativa, cualitativa, estadística, geográfico-ambiental y territorial.

La periodicidad de la revista no fue la esperada; tuvo problemas por falta de presupuesto en diversas ocasiones, por lo que su publicación estuvo marcada por la discontinuidad. Cuando en 1925 Mendieta se convirtió en su editor, no obstante, había logrado articular programáticamente el discurso que sería la justificación posterior de la sociología en sus primeros años de existencia como disciplina institucionalizada en México: el estudio de los grupos de población “aborígenes", sus características físicas y geográficas, su medio ambiente social, no sólo como problemas científicos, sino de orden político y social. En su último número Lucio Mendieta publicó una pequeña nota en la que llamaba la atención precisamente sobre este tema. Reconocía que habían sido intelectuales extranjeros los que se habían dedicado al estudio de las poblaciones indígenas, pero que era sobre todo a los políticos del país, a los que debía interesarles su conocimiento científico, puesto que dentro del estado, los indígenas "formaban grupos sin coherencia con el resto de la población". Como se señaló antes, el propósito normativo fue la f en Méxusión racial, la unificación del idioma y de las costumbres, sin las que Lucio Mendieta, junto a Gamio, pensó que no podía existir ni patria, ni nacionalidad. Lo que discursivamente se presentó como los objetivos científicos de la antropología para el país, coincidía plenamente con los fines por la Dirección de Antropología desde su fundación: el estudio de los indígenas para encontrar las vías mas adecuadas para integrarlos a la civilización contemporánea. (Mendieta, 1925, p. 43).

Hubo otra experiencia editorial que, si bien no involucró a Mendieta directamente como sí fue el caso de Ethnos, formó parte de su horizonte intelectual como integrante del gremio de los abogados. Dos años después de la fundación de Ethnos fue fundada otra importante publicación antecesora, específicamente en el espacio institucional del derecho: la Revista de Ciencias Sociales (RCS), auspiciada por las autoridades de la Escuela Nacional de Jurisprudencia de la Universidad Nacional. El primer número se publicó en 1922, bajo la iniciativa y dirección de Daniel Cosío Villegas y un consejo de redacción formado por profesores y alumnos. Al igual que ocurrió con la Ethnos, RCS buscó promover estudios sociales de la realidad social 
mexicana: medio geográfico, raza, población, división del trabajo y educación. Se trató de conocer objetivamente la especificidad nacional, en un contexto en el que había un gran desconocimiento de las estructuras y procesos que definían los condicionamientos y problemas que enfrentaba un país embarcado en un proceso acelerado de transformaciones de diverso signo. Esta publicación trató de llamar la atención sobre la necesidad de generar un saber sobre lo propio, alejado de la abstracción generalizante ${ }^{3}$ y, paralelamente, contribuir al reconocimiento de que uno de los problemas fundamentales que enfrentaba este tipo de investigaciones, era la dificultad de acceder al conocimiento acumulado por las ciencias sociales en Europa y Estados Unidos. Estos líderes fundadores sabían que las ciencias sociales a nivel local no comenzaban de cero y desplegaron grandes esfuerzos para crear condiciones favorables a la recepción de estos legados. En este sentido debe entenderse, por ejemplo, la colaboración de Daniel Cosío Villegas en el primer número, orientada a informar a los abogados que presumiblemente habrían de efectuar el estudio de la sociedad mexicana, de una bibliografía especializada en la figuraban obras de Giddings, Rousseau, Durkheim, Spencer, Tarde, Ward, Bouglé, entre otros autores relevantes de la época ${ }^{4}$. Durante su primer año RCS publicó pequeños escritos sobre el sistema constitucional, la psicología del movimiento obrero, el subsuelo, las reformas al código civil, todos ellos abordados, sin duda, en un registro juridicista. Sin embargo, se pueden identificar ya desde entonces ramificaciones discursivas que, menos de una década después, conducirían a la formación de la economía y la sociología como ciencias independientes con un cobijo institucional propio. ${ }^{5}$ El formato de la $R C S$ incluyó un cuerpo de artículos, reseñas y listas bibliográficas. Aunque los contenidos fueron fundamentalmente juridicistas, en estas dos últimas secciones pueden rastrearse algunos indicios de los incipientes procesos de transferencias internacionales de conocimiento especializado en ciencias sociales que tanta importancia cobrarían de los años cuarenta en adelante, sobre todo en la RMS.

3. Una característica de estas publicaciones pioneras fue la defensa de la nación. Por ejemplo, en el primer número, Antonio Caso sostuvo que el pensamiento extranjero, por más vasto e imparcial que fuera, no podía conocer "el alma colectiva de la nación". Ver Caso (1922, p. 2). Esto no significaba desdeñar lo acumulado en estos campos, sino recibirlo y usar lo pertinente, adaptándolo a las coordenadas locales. La aspiración era contar con ciencias sociales alimentadas del pensamiento universal, pero arraigadas en sus propias realidades.

4. Ver Cosío Villegas (1922).

5. Al igual que Ethnos, la RCS tuvo una periodicidad irregular por problemas de tipo financiero. Cada número implicaba grandes dificultades, el último fue publicado en 1933. 


\section{Conocimiento y poder público}

La dependencia de la sociología del poder público explica que, en sus años fundacionales, se dirigiera a la formulación de un discurso mas normativo que disciplinar. La pretensión de sus principales líderes, generalmente abogados, fue orientar los procesos de transformación social, influir en la toma de decisiones políticas, ganar espacios para estas ciencias y, qué duda cabe, también obtener reconocimiento, pertenencia, prestigio, poder e influencia. Se trataba de convertir un saber racional sobre la sociedad en proveedor de criterios para la toma de decisiones políticas. En este sentido, la sociología se definió en los años iniciales del liderazgo de Lucio Mendieta como una ciencia comprometida con la revolución, con la nación, con el progreso y con la patria, entendidas como conceptos de movimiento y de expectativa, como categorías políticas de acción que darían fundamento a proyectos de cambio que se pensó llevarían al país, en futuros cercanos, a lo que para Estados Unidos y Europa era ya experiencia presente: el desarrollo económico, el bienestar material, la educación. Como observadores de este tramo de los itinerarios de la sociología en México, sabemos que los saberes producidos por nuestra disciplina en estos años, lejos estuvieron de ser eficientes en términos instrumentales para la política pero, indudablemente, tuvieron la capacidad de proveer de legitimación simbólica a una buena parte de sus proyectos ante los ojos de la sociedad y del poder público, cuyo apoyo material y simbólico fue fundamental para su institucionalización. Así, este primer saber sociológico fue presentado como un conocimiento experto frente al cual el sentido común y la empiria era deficitarias. El efecto de sentido que se buscó producir fue que la sociología y las ciencias sociales eran los instrumentos cognitivos mas adecuados para encaminar al país por la ruta del progreso y el bienestar social. El espacio institucional que daría cobijo a la sociología y las ciencias sociales en estas coordenadas, fue la Universidad Nacional.

Desde los años treinta fue ganando peso un discurso que enfatizó que la universidad debía estar cerca de las demandas del pueblo, de la nación. En 1936, tres años antes de asumir la dirección del IIs, Lucio Mendieta publicó La universidad creadora; en esta obra reflexiona sobre la responsabilidad que pensaba que debía asumir esta institución ante la sociedad posrevolucionaria. Específicamente, propuso que la Universidad Nacional debía asumir sus tareas como una misión saturada de implicaciones morales, éticas y de un conjunto de responsabilidades ante la sociedad, particularmente, frente a los jóvenes que tenía que preparar para el futuro. Sostuvo que los problemas universitarios tenían su origen la ausencia de esta orientación entre sus profesores y propuso para solucionarlo, lo que ahora llamaríamos la profesionalización de la enseñanza y la investigación, sugiriendo la formación de un 
nuevo tipo de docente que se caracterizaría por apartarse de la "abstracción vacía y teorizante" (Mendieta, 1936). Para que las nuevas generaciones fueran capaces de realizar el sueño de una sociedad mejor, había que generar textos universitarios producidos por los propios profesores, textos en los que quedara registro de un conocimiento situado de la propia realidad. Una de las dificultades que identificó tempranamente Mendieta en los procesos de formación de los universitarios, fue el que los libros fundamentales que estructuraban sus aprendizajes, estaban escritos en otros idiomas y que, además, la enseñanza de otras lenguas era sumamente precaria. Consideró que la tradición oral de la cátedra que resumía diferentes autores a los alumnos improvisando y omitiendo fuentes era un obstáculo a la modernización de la enseñanza. Abogó por la instauración de nuevas prácticas, centradas en la escritura, la publicación, por encarar la docencia (y la investigación) como empresas colectivas, producto de "equipos" intelectuales, de una división intelectual del trabajo eficiente, de procesos de transmisión que realmente contribuyeran a transformar orientaciones y proyectos. El lugar privilegiado para ello era, indudablemente, la Universidad Nacional que, una vez transformada bajo este conjunto de expectativas, dejaría atrás al "sabio egoísta" del pasado, para crear un tipo social nuevo: el experto como actor fundamental de la política, como parte de una interrelación entre conocimiento y poder que fuera útil a la nación. De esta forma, sostuvo Mendieta, la nueva investigación científica que se cultivaría en la Universidad Nacional podría cumplir un propósito que se consideró imperativo en estos años: el descubrimiento integral del México ignorado y de las fuerzas que le podrían salvar y redimir. Así, el saber científico se postuló como un patrón de orientación temporal y espacial: el futuro de la patria dependería en buena medida, de los universitarios, a los cuales estaba reservada una misión de corte colectivo que atravesaba -imaginariamente- las identificaciones parciales para disolverlas en una unidad nacional que las integraría a través de los procesos de modernización económica, política y cultural que el propio saber universitario debía de orientar.

Lo anterior permite comprender que, en muchos sentidos, y a diferencia de Estados Unidos y Europa, la sociología en México puede ser considerada en su primera etapa de institucionalización, como una ciencia de estado articulada alrededor de una íntima colaboración entre conocimiento y poder público. Esto significa que la sociología en México se institucionaliza con una sobrecarga de expectativas provenientes de la urgencia práctica que impuso la etapa reconstructiva de la Revolución Mexicana que condicionó, en buena medida, el tipo de organización que se daría, la formación de su primer patrimonio conceptual, el perfil de sus primeros liderazgos, las temáticas de sus primeros ejercicios de investigación y sus relaciones con los regímenes posteriores a la revolución. Para Lucio Mendieta y su generación, los 
cambios que experimentó el país entre los años veinte y treinta, fueron estímulos para reflexionar sobre las posibilidades de instauración de nuevos futuros. Pensó que la justificación político-práctica de la sociología radicaba en la aceleración del progreso, la modernización de la patria, el cumplimiento del programa social de la Constitución de 1917 que reconocía los derechos de campesinos y trabajadores, así como la integración de una nacionalidad homogénea capaz de dar sentido y dirección a la acción colectiva.

En este contexto de época Lucio Mendieta asumió que era indispensable la producción de un conocimiento empírico sobre una sociedad desestructurada por la lucha armada. La sociología podía y debía tener como propósito central la aportación de soluciones a los principales problemas de la sociedad. Aquí radicó para este abogado-sociólogo el sentido y justificación de la existencia de esta ciencia en un país que tenía frente a sí, no sólo la tarea de retejer los hilos rotos de la socialidad, sino también emprender procesos de modernización locales de manera acelerada, a fin de que la patria se acercara en un futuro cercano a los países y regiones para los cuales el progreso era ya experiencia presente, es decir, Estados Unidos y Europa. Lucio Mendieta partió de la convicción de que México sufría, como otros países de América Latina, de un empirismo político que era la causa de sus principales problemas y que esto podría superarse cuando su vida, social y económica estuviera sustentada en un conocimiento sociológico preciso. Es decir, cuando esta disciplina diera un fundamento científico a una nueva política. Pensó que no era posible gobernar adecuadamente un país cuyas estructuras eran desconocidas. La tarea que se propuso, en consecuencia, fue contribuir a la formación de instituciones y de un clima intelectual orientados a cubrir esta carencia cognitiva. Estas convicciones fueron compartidas por reconocidos abogados e intelectuales de la época a los que se debió la institucionalización de otras ciencias afines, por ejemplo, la economía: Daniel Cosío Villegas, Jesús Silva Herzog y Eduardo Villaseñor, entre los más importantes.

La formación de un primer acervo de conocimiento escriturario:

La investigación de los indígenas y la Revista Mexicana de Sociología

Precedido de un gran prestigio como experto en cuestiones indígenas y en derecho agrario, Mendieta y Núñez fue nombrado director del IIs en 1939, sucediendo en este puesto a Manuel Gamio, que para entonces era Subsecretario de Educación. Este espacio de investigación fue fundado desde 1930, pero en realidad adquirió forma como tal hasta que nuestro personaje asumió su dirección. Lucio Mendieta estructuró una institución orientada a la investigación empírica de lo que desde los años de su relación con Manuel Gamio se consideró el principal problema del país: 
la desigualdad étnica, concebida como un obstáculo para la inserción del conjunto de la nación en la ruta de la modernización y el progreso. Definió la sociología aplicada como el interés central del IIs, bajo un esquema organizativo en el que se abordarían el estudio teórico de las cuestiones sociales, la adaptación de los métodos sociológicos a la realidad nacional, al tiempo que se definirían "planes detallados de investigación concretamente enfocados" a casos particulares. En una segunda etapa, tendría lugar el desarrollo en "el terreno mismo de los hechos" de los programas de investigación derivados de lo anterior. Finalmente, habría de efectuarse el análisis de los datos arrojados por la investigación, para extraer conclusiones, proposiciones y proyectos de acción. (Mendieta, 1939, p.3). A partir de la llegada de Lucio Mendieta a la dirección del IIs, se formaron cinco secciones: Sociología, Medicina Social, Ingeniería y Arquitectura Social, Economía y Trabajo, Biblioteca y, por último, Relaciones Exteriores. Es evidente aquí la inexistencia de fronteras disciplinarias claras para la sociología; no obstante, Mendieta justifico esta estructura bajo el argumento de que los fenómenos sociales suponían dimensiones variadas que reclamaban la concurrencia de varias ciencias en su estudio (Mendieta, 1939b, p. 7).

No es posible entrar aquí al examen del tipo de trabajo que propuso para cada una de estas secciones este líder institucional pero es necesario, al menos señalar, la orientación que impuso a la Sección de Archivo, Biblioteca y Relaciones Exteriores, por el impulso que dio al paso de una cultura oral a otra de corte escriturario, cimentando con ello el posterior paso a la formación de una primera literatura especializada para la sociología con posibilidades de transmisión y acumulación. Esta sección tendría como función principal resguardar, conservar y clasificar el material de investigación que se fuese generando. De importancia central fue la creación de una biblioteca especializada de sociología orientada a inventariar sistemáticamente las referencias, libros, documentos y notas que los investigadores necesitarían para sus indagaciones empíricas. En este registro, se buscaría también cultivar "relaciones con los centros científicos y con los intelectuales del país y del extranjero que se han consagrado al trabajo social" (Mendieta, 1939, p. 11).

Las preguntas centrales del trabajo de investigación inicial del IIs fueron ¿quiénes eran los indios y qué requerían para integrarse/disolverse en la nación? Esta faceta del trabajo de Lucio Mendieta y Núñez en el IIs y la RMS se caracterizó por una sobreobservación de los indígenas que tuvo como contraparte, a pesar de su énfasis discursivo en la necesidad de estudiar los problemas de la sociedad mexicana, el descuido del análisis de otras cuestiones importantes de la época, como los procesos migratorios, el crecimiento de las ciudades, el sindicalismo, los problemas ligados al corporativismo propio de los regímenes revolucionarios y los obstáculos estructurales a la modernización, entre otros. En este sentido, la sociología cultivada 
por Mendieta y Núñez quedó por detrás de disciplinas institucionalizadas también en los años treinta, como la economía, que dieron una gran importancia al análisis empírico de estas cuestiones.

Al llegar a la dirección del IIs Lucio Mendieta pudo reconducir la experiencia organizativa, de investigación y de edición obtenida a través de su relación con Manuel Gamio, al campo de la sociología. Sin ello, los proyectos que emprendió difícilmente hubieran tenido el éxito que tuvieron, dentro y fuera de la Universidad Nacional. Como parte de la reorganización de los proyectos de investigación de este espacio de investigación, Mendieta fundó la Revista Mexicana de Sociología como una revista especializada dirigida a dar a conocer los resultados de las investigaciones del IIs, a estimular la indagación sociológica en México, a estrechar relaciones con practicantes de otros países y promover intercambios con las principales instituciones dedicadas al estudio de las ciencias sociales, así como a dar a conocer los "más recientes estudios de sociólogos modernos de Europa y América" (Mendieta, 1947, p. 427). Como en su momento se lo propuso Ethnos, la RMS buscó desde su primer número contribuir a un deslinde del empirismo del que "sufrían nuestros países" y que consideraba una de las raíces del atraso de México y América Latina; generar la convicción en el gobierno y la sociedad en general, de que la investigación sociológica debía ser la base de una nueva política no sólo en el país, sino en toda la región; integrar una comunidad de practicantes comprometida con este proyecto de ciencia. Esta comunidad estaría integrada por figuras como Ricardo Levene, de la Universidad de Buenos Aires; Raúl Orgaz, de la Universidad de Córdova; Manuel Diéguez, historiador y sociólogo brasileño; Roberto Agramonte, de la Universidad de La Habana; Óscar Alvárez Andrews, de la Universidad de Chile, al igual que el brasileño Mario Linz. Del lado de los mexicanos figuraron Francisco Rojas González, Roberto de la Cerda, René Barragán, Arturo González Bonilla y Emilio Uribe Ramos, principalmente. Incluso, pudo Lucio Mendieta contar en no pocas ocasiones, con la participación de Pitirim Sorokin de la Universidad de Harvard y Robert Redfield, de la Universidad de Chicago, como colaboradores de la RMS o participantes en algunas reuniones y eventos. Este conjunto de personajes fueron parte de lo que podría llamarse el "colegio invisible" que, poniendo en juego vínculos formales e informales, definió en estos años fundacionales lo que se consideraba sociología, lo que podía y debía adscribirse a esta disciplina, estableciendo con ello los límites de lo pensable (De Certeau, 1987).

En estas coordenadas el estudio empírico de los indígenas fue el fundamento de la justificación de la sociología como campo de conocimiento institucionalizado. Las preguntas iniciales a las que trataron de responder estas investigaciones fueron ¿quiénes eran los indígenas? ¿dónde y cómo vivían? ¿cuántas etnias existían en el 
país? ¿cómo podían ser integrados al desarrollo nacional? En los gobiernos de la época existía la convicción de que era necesario incorporar económica y socialmente a los indígenas para que los procesos de modernización locales pudiesen conducir a la sociedad, en algún momento, por la vía del progreso. La construcción de un México moderno los modos de vida de los indígenas eran considerados una rémora proveniente de un pasado que tenía que ser disuelto para conseguir estos propósitos. Los resultados de la investigación de los indios fueron publicados como artículos principalmente en la Revista Mexicana de Sociologia (RMS), fundada en 1939 por el propio Mendieta cuando se convirtió en director del IIs. Además se elaboraron cerca de 50 monografías sobre las características socioeconómicas y culturales de las etnias del país y se publicaron libros que daban cuenta de sus costumbres, historia y formas de vida; de ello se desprendieron orientaciones político-prácticas para eliminar los comportamientos que no contribuían a la modernización del país. A nivel normativo, esto implicó un proyecto civilizador que justificó la existencia de la sociología como ciencia frente a la sociedad. Este conjunto de trabajos se presentó como una aportación a la obra indigenista de los gobiernos posrevolucionarios. La gran importancia que tuvo la descripción empírica de los indígenas para el IIs en estos años puede verse, no sólo en medio centenar de artículos publicados sobre este tema en los años cuarenta, las monografías breves o los atlas etnográficos que se editaron, sino también en un conjunto de eventos públicos dirigidos a la difusión de estos resultados, como exposiciones fotográficas, conferencias y muestras etnográficas que fueron organizadas por la Universidad Nacional a través del IIs. Estos eventos fueron representaciones públicas de una disciplina que buscaba mostrar al gobierno y a la sociedad su utilidad, su pertinencia práctico-política. El resultado fue la formación de un acervo de conocimiento, fijado textualmente principalmente en las páginas de la $R M S$, sobre amplios grupos sociales que, efectivamente, eran completamente desconocidos empíricamente en esos años.

La creación de la Escuela Nacional de Ciencias Políticas y Sociales

En conjunto puede afirmarse que hacia principios de la década de los años cincuenta, el liderazgo de Lucio Mendieta en el IIS y la RMS había cristalizado en un conjunto de condiciones extremadamente favorables para extender sus redes de influencia a nivel nacional y latinoamericano. Asistió como representante de la Universidad Nacional al Primer Congreso Internacional de Ciencia Política de 1948, promovido por la Unesco, en el que se acordó favorecer la creación de institutos y escuelas de sociología en los países atrasados. Esto ocurrió en los años de la posguerra, bajo el propósito geopolítico de que los países menos desarrollados lograran, con el 
auxilio del conocimiento científico, un progreso suficiente para mantenerlos bajo el horizonte normativo occidental. Como es sabido, estos fueron los años de mayor expansión institucional de las ciencias sociales a nivel mundial, impulso que se combinó con las características, tradiciones, liderazgos y expectativas locales preexistentes.

Lucio Mendieta se encargó de la elaboración del proyecto que daría lugar a la fundación de la ENCPys. Con la apertura de esta escuela, en 1951, México contó con programas universitarios estables dirigidos a formar practicantes profesionales de las ciencias sociales. Esto significó un avance crucial para la sociología como disciplina autónoma, sobre todo porque durante muchos años fue sólo una materia complementaria en la formación de los bachilleres, los abogados y, posteriormente, de los economistas. Él mismo redactó los planes y programas correspondientes a las carreras que impartió la escuela inicialmente: ciencias sociales (sociología), diplomacia, periodismo y ciencia política. Los contenidos descansaron sobre todo en el derecho, la antropología, la geografía humana, la criminología y la enseñanza de lenguas extranjeras. Este primer proyecto de formación de científicos sociales se integró tomando en cuenta también los enfoques y materias de disciplinas de carácter humanístico, así como la herencia de la tradición naturalista de la sociología norteamericana dominante en esos años. El programa docente a nivel licenciatura quedó cobijado en una estructura universitaria que separaba tajantemente la docencia de la indagación empírica.

Desde el punto de vista de la observación, los planes y programas de estudios son construcciones discursivas elaboradas intersubjetivamente por una comunidad disciplinar o profesional; en ellos se fijan orígenes, demarcaciones, objetos, metodologías, lenguajes, literaturas canónicas, problemas centrales y procedimientos reglamentados para la práctica profesional y disciplinar. En otras palabras, son un acuerdo orientado a aportar un mapa de conocimiento coherente que sea un medio de socialización intelectual para futuros practicantes, a los que se forma en lo que se considera lo fundamental del patrimonio de conocimiento de la ciencia en caso. En los años de la elaboración, discusión y aprobación de estos documentos como condición para la apertura de la ENCPys, Lucio Mendieta era el líder vertical de la comunidad de abogados-sociólogos que se hizo cargo de la institucionalización de esta ciencia en México, con todas las limitaciones de su contexto, que no fueron pocas. El liderazgo derivado del lugar social que ocupó en el IIs y de su trayectoria institucional constituyó el entramado de interdependencias en el que fue posible que fuese el encargado de redactar personalmente este conjunto de documentos. En ellos, quedó delineada una primera idea de lo que podía ser la sociología como profesión en México, sin lograr todavía un desprendimiento de las matrices de la antropología, la etnografía, la jurisprudencia y la criminología. Prueba de ello es que los primeros 
dos años de los cuatro que comprendió la carrera de Ciencias Sociales, se organizaron alrededor de un tronco común también a las licenciaturas en ciencia política, diplomacia y periodismo, así como el peso que tuvo la enseñanza de lenguas extranjeras para las primeras generaciones de la ENCPys. Otra evidencia de la fragilidad interna de la sociología en estos años fue, por ejemplo, el que no existiera una planta docente propia, por lo que muchos de sus cursos hubieron de impartirse en las facultades de Filosofía y de Derecho de la Universidad Nacional, de donde procedían la mayoría de los profesores. La comunidad agregada alrededor de Mendieta y Núñez, del IIs y de la $R M S$, aunque consolidada, era demasiado pequeña para hacerse cargo de la formación de los primeros reclutas universitarios de la sociología en México.

No obstante la falta de una demarcación disciplinaria de corte sociológico en estos primeros planes y programas, debe mencionarse que hubo un pequeño grupo de asignaturas en las que comenzaría a germinar un perfil protosociológico; fue este el caso de los cursos de sociología general y sociologías especializadas, así como las relativas a métodos de investigación social y de estadística general, junto con estadística social. Este grupo de materias sería el que se reforzaría, cuando este primer plan experimentó su primera reforma hacia finales de los años cincuenta, cuando Pablo González Casanova (hijo) se convirtió en director de la ENCPys, con lo cual deslindaría en definitiva a la sociología de las matrices de la antropología y el derecho. Debe señalarse que la apertura de esta escuela fue apenas el comienzo de un lento proceso de consolidación de la formación profesional de sociólogos en México, como muestra el hecho de que hacia mediados de los años sesenta del siglo xx había menos de 20 sociólogos titulados. El promedio de titulación anual era de 3 , contra 18 o 20 de los economistas y 250 de los abogados (Olvera, 2013). Sería hasta los años sesenta cuando la sociología en México encontraría condiciones propicias para iniciar el lento proceso que le condujo una década después, a un crecimiento acelerado de su matrícula a nivel nacional.

Normativamente, la Universidad Nacional buscó con la creación de la ENCPys, robustecer su marco cultural, sumando a la enseñanza de las "ciencias exactas" las de carácter social, con la intención de resolver los problemas que aquejaban a México y el mundo en los años de la posguerra. En el discurso inaugural de esta escuela, el rector Luis Garrido hizo referencia a la necesidad de que estas ciencias, bajo la forma de profesiones universitarias, aportaran los elementos necesarios para integrar sistemas de organización social que hicieran posible el "disfrute pacífico, equitativo, equilibrado y racional” de las conquistas del progreso (Ludlow, 1984, p. 107). La sociología y las ciencias sociales, como en su momento había ocurrido también con la economía y con la antropología, se instauraron como profesiones bajo coordenadas orientadas a transformar y mejorar la sociedad. Independientemente de los resultados 
de estos propósitos, estas demandas extradisciplinarias fueron una condición sin la cual estas ciencias no hubieran tenido una primera existencia institucional como carreras universitarias.

\section{Conclusión}

Lucio Mendieta fue un intelectual cuya trayectoria sólo puede entenderse en el horizonte de expectativas de futuro abierto por el triunfo de la Revolución de 1910. La experiencia de haber sido testigo de la revolución mexicana como estudiante de la Escuela Nacional de Jurisprudencia, el contacto directo con los indígenas a través de su colaboración con Manuel Gamio y, desde luego, la formación positivista obtenida en la Escuela Nacional Preparatoria de la Universidad Nacional, fueron los ejes de una socialización intelectual que le posibilitó convertirse en el líder institucional de mayor influencia y peso que ha tenido la sociología en Mexico, independientemente de su estatus de personaje semi-desconocido dentro de la propia comunidad de practicantes de esta disciplina en nuestro país. Se debe a él, y al círculo de abogadossociólogos mexicanos y latinoamericanos de los que se rodeó, la formación de un primer discurso sociológico que, con todo y las insuficiencias que sería fácil imputarle si aplicáramos retroactivamente nuestros propios criterios de cientificidad, logró el reconocimiento institucional para la sociología y las ciencias sociales en México. No desconocemos la importancia que tuvieron, antes que Mendieta, las reflexiones de los abogados, ingenieros y médicos que se acercaron a la historia, a la antropología, a la economía y otras ciencias para tratar de hacer inteligible la realidad mexicana de finales del siglo XIX y principios del siglo XX, como Justo Sierra, Andrés Molina Enríquez, Ricardo García Granados, Porfirio Parra o Julio Guerrero, por mencionar sólo algunos de los más conocidos personajes de la etapa de precursores. De ellos recibió también Mendieta, legados y herencias que, bajo el horizonte de la revolución y bajo la influencia del trabajo de la antropología, le llevó a la fijación de un primer objeto de investigación empírica para una ciencia recientemente institucionalizada, cuando en los años cuarenta se volcó a la descripción de los indígenas. Entre 1939 y 1965, cuando Lucio Mendieta deja las direcciones del IIs y de la RMS para dar paso a la primera generación de científicos sociales de formación bajo el liderazgo de Pablo González Casanova, la sociología en México logró pasar de la etapa de precursores individuales, a la de institucionalización inicial, aportando con ello un legado invaluable para esta disciplina en México. El relevo generacional había comenzado varios años antes, cuando en 1957 Pablo González Casanova fue nombrado director de la ENCPys y se dio a la tarea de reformar los planes y programas de estudio elaborados por Lucio Mendieta y Núñez, con el propósito de demarcar con mayor claridad el 
campo disciplinar y profesional de las ciencias sociales en México y desprenderlo, en definitiva, de las coordenadas del juridicismo (Castañeda, 2004) y del control de los abogados. En 1965 comienza un proceso de pérdida de significación de la herencia de los abogados-sociólogos frente a las nuevas generaciones de practicantes que consideraron que sus herramientas cognitivas no eran útiles para explicar los cambios que atravesaron a México, a América Latina y al mundo en general en esta turbulenta década. Esto explica por qué la obra institucional de Lucio Mendieta entró en un largo periodo de desconocimiento y olvido, a pesar de la relevancia de sus aportes. Hubo de transcurrir un largo periodo para que, ya en las etapas de profesionalización y especialización, la sociología en México estuviera en condiciones de volver sobre el espacio de experiencia pasado, para convertir algunos de sus tramos en objeto de investigación y resignificar, al menos parcialmente, sus legados y antecesores más relevantes, entre ellos, Lucio Mendieta y Núñez.

Hoy es posible reconocer en este personaje un antecesor central de la sociología en México e identificar cómo sus iniciativas y proyectos condicionaron su desarrollo, limitaciones y posibilidades entre 1939 y 1965 . El conocimiento de su obra institucional -producto de su época y de un liderazgo vertical y corporativo-es imprescindible para explicar los procesos de transmisión intelectual que posibilitaron indirectamente que la sociología en México, setenta y cinco años después de su llegada de Mendieta a la dirección del IIs tenga hoy un perfil más profesional y robusto, si bien no exento de fisuras. La importancia de volver sobre las huellas de las etapas anteriores de la sociología y de sus figuras más importantes, radica en que una autocomprensión contemporánea de la disciplina debe reconocer la forma como su experiencia pasada se entrelaza con su presente y con su horizonte de futuro. La sociología especializada, profesionalizada y, frecuentemente, fragmentada que es el horizonte de nuestras prácticas es, paradójicamente, no sólo la que dificulta la articulación de conexiones significativas pasado-presente-futuro, sino también la que posibilita que el espacio de experiencia de los antecesores pueda hoy ser objeto de investigación legítima y pertinente en nuestros campos intelectuales. 


\section{Referencias Bibliográficas}

Agramonte, Roberto. (1961), Lucio Mendieta y su magisterio sociológico. Ciudad de México, Cultura.

Caso, Antonio. (1922), “Los estudios sociales”. Revista de Ciencias Sociales, 1 (I), jul.

Castañeda Sabido, Fernando. (2004), La crisis de la sociología académica en México. Ciudad de México, Porrúa.

Cosío Villegas, Daniel. (1922), “Bibliografía sociológica”. Revista de Ciencias Sociales, 1 (I), jul. De Certeau, Michel. (1987), La escritura de la historia. México, Universidad Iberoamericana. Koselleck, Reinhart. (1993), Futuro pasado. Buenos Aires, Paidós. . (2001), Aceleración, prognosis y secularización. Valencia, Pre-Textos.

Ludlow, Leonor. (1984), "Documentos: 33 años de historia de la Facultad de Ciencias Políticas y Sociales". Revista Mexicana de Ciencias Politicas y Sociales, 115.

Mendieta y NúÑez, Lucio. (1923), El problema agrario en México. Ciudad de México, Porrúa. (1925), "Importancia científica y práctica de los estudios etnológicos y etnográficos". Ethnos, 3 (I), mar.-abr. . (1938), La economía del indio. Ciudad de México, Departamento de Asuntos Indígenas. (1939), La habitación indigena. Ciudad de México, Imprenta Universitaria.

. (1939b), "El Instituto de Investigaciones Sociales de la Universidad Nacional”. Revista Mexicana de Sociología, 1 (1), mar.-abr.

. (1942), "Programa para la integración de la investigación social en las Américas". Revista Mexicana de Sociología, 1 (IV): 125-137, jan.-mar.

. (1947), "Memoria del Instituto de Investigaciones Sociales de la Universidad Nacional". Revista Mexicana de Sociología, 3 (Ix), set.-dez. . (1949), Los Zapotecos. Ciudad de México, Imprenta Universitaria. . (1950), Estudios sociológicos. Primer Congreso Nacional de Sociología. Ciudad de México, IIs/Unam.

. (1951), Teoría de los agrupamientos sociales. México, Porrúa.

Moya López, Laura A. (2013), José Medina Echavarría y la sociología como ciencia social concreta. 1939-1980. Ciudad de México, El Colegio de México.

Olvera Serrano, Margarita. (2004), Lucio Mendieta y la institucionalización de la sociología en México. Ciudad de México, Porrúa.

. (2013), Economía y sociología en México: revistas especializadas, liderazgos y procesos de institucionalización (1928-1959). Ciudad de México, Universidad Autónoma Metropolitana.

Reynoso Jaimes, Irving. (2013), "Manuel Gamio y las bases de la política indigenista en México". Andamios, 22 (10): 333-355, maio-ago.

Vázquez de Knauth, Josefina. (1970). Nacionalismo y educación en México. Ciudad de México, El Colegio de México. 


\section{Resumen}

Los aportes de Lucío Mendieta y Núñez a la institucionalización de la sociología en México (1939-1951)

Lucio Mendieta y Núñez es considerado el líder de la institucionalización de la sociología en México como disciplina autónoma independiente reconocida a nivel universitario. Este artículo analiza los momentos cruciales de su trayectoria.

Palabras claves: Institucionalización; Sociología; Lucio Mendieta y Núñez; México.

\section{Resumo}

As contribuições de Lucío Mendieta y Núñez à institucionalização da sociologia no México (1939-1951)

Lucio Mendieta y Núñez é considerado o líder do processo de institucionalização da sociologia no México como disciplina autônoma universitária. Este artigo analisa os momentos cruciais de sua trajetória.

Palavras-chave: Institucionalização; Sociologia; Lucio Mendieta y Núñez; México.

\section{Abstract}

Lucio Mendieta y Núñez' contributions to institutionalization of sociology in México (1939-1951)

Lucio Mendieta y Núñez is considered the leader of the institutionalization of sociology in México as an autonomous independent discipline, recognized at the university level. This article analyzes the crucial moments of his trajectory.

Keywords: Institutionalization; Sociology; Lucio Mendieta y Núñez; México.

Texto recebido em 29/2/2016 e aprovado em 16/3/2016. DoI: 10.11606/0103-2070. ts.2016.111594.

MARGARITA OLVERA SERRANO es profesora del Departamento de Sociología en el Universidad Autónoma Metropolitana-Azcapotzalco E-mail: habril9@prodigy.net.mx. 